\title{
Open and Distance Learning for the Professional Development of English Teachers in Chinese Higher Education
}

\author{
Chunyan BAO \\ Humanity Department, City College of WUST, Wuhan, 430083, China \\ Email: qy0618@126.com
}

Keywords: open and distance learning; teacher professional development; English; higher education; model

\begin{abstract}
Teacher professional development and open and distance learning both convey the idea of lifelong learning, and thus were linked together. The pressure of a reform in China's College English teaching was discussed, which requires teachers grasp the chance of distance learning. To make use of the communication technology and achieve the goals of teachers' professional development, the author proposed an interactive model that contains four dimensions of interaction: learner with learner, learner with instructor, learner with content and learner with teacher in practice.
\end{abstract}

\section{Introduction}

Distance learning, different from traditional face-to-face teaching and learning, is a method that breaks the limit of time and space, in which the teaching is conducted by teachers separated from learners in location and time. The learning resources-including books, course-related materials, assignments and tests-are distributed and then collected, if necessary, through express delivery and the Internet, with particular emphasis for the latter. The openness of distance education allows learners to choose what, when and where to learn, as well as how fast a course is completed. For learners, open and distance learning, or ODL, is a good way to reconcile work and family responsibilities with educational needs.

Teacher professional development (TPD) refers to activities that help to boost a person's formal experience, pedagogical skills, subject-matter knowledge, teaching expertise, individual satisfaction and other characteristics as a teacher. For decades, many countries have been carrying out educational reforms. One of the top concerns of these reforms is the professional development of teachers. More and more societies are acknowledging that TPD is a significant means of reaching the basic goals of educational endeavors.

Obviously, ODL is a method and TPD is a practical activity. Is it possible to use this method in performing the activity? How can they be related to each other? In what ways can TPD be fulfilled with the support of ODL? These are major questions to be answered in the following parts.

\section{Internal relationship between ODL and TPD}

The world is dynamic. If there is anything that is eternal and unchanging, it is change itself. If humans long for the survivability and long-term existence, they must develop the perspective that learning never ends.

Since the world entered the information age, the importance of "lifelong learning" (LLL) has become prominent. Wikipedia defines lifelong learning as "the continuous building of skills and knowledge throughout the life of an individual". This definition, to some extent, has points of resemblance to that of TPD: both put emphasis on the necessity of developing a person's skills and knowledge. To be exact, the professional development of teachers is a career-long process which begins with the teacher education in formal institutes and continues until retirement. And therefore, TPD is one aspect and a part of lifelong learning.

Meanwhile, in this age of lifelong learning, open and distance learning is constantly changing the rules for higher education, executive training and employee development generally. ODL is a 
means of providing learning opportunities to everyone, anytime, anywhere in the world with internet access.

LLL, as a requirement and an ideal for social advances, has knitted ODL and TPD together.

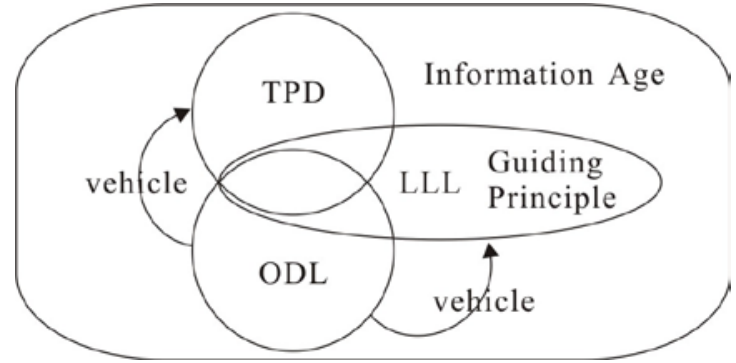

Figure 1. The relationship among ODL, TPD and LLL.

As is shown in the above figure:

(1) The three terms - lifelong learning, open and distance learning and teacher professional development, came into being under the same social and historical background, that is, the information age.

(2) Lifelong learning is a guiding principle for anyone who expects to keep up with the changing society. It has a universal value that ODL and TPD hope to convey to their recipients.

(3) By making learning attainable anytime and anywhere, open and distance learning is a powerful tool and a major vehicle for fulfilling lifelong learning and the professional development of teachers.

\section{Challenges and chances facing english teachers of Chinese higher education}

For all the beneficiaries of Chinese higher education, the prestige and privilege enjoyed by English is obvious. From the macro perspective, English is a means for realizing Chinese modernization and a bridge for international communications. From the micro perspective, English is a key to many enviable personal opportunities, such as working abroad, or in foreign-invested companies or in joint ventures.

But in recent decades, English teaching in Chinese colleges and universities is facing great challenges: students' general English proficiency is improving as a result of a more frequent exposure to English through newspapers, ads, TV programs, movies and music; modern information technology has posed both threats and opportunities. In brief, English teaching has entered an age of endless turmoil.

\section{A. English+Subject: Destiny of ELT Revolution}

Some people may argue that ESP, bilingual education and CLIL have stirred up a turbulence long before but are yet to take the place of ELT, thus, there is no possibility that they become a mainstream in English teaching. However, qualitative changes always hide behind quantitative changes. When more and more people doubt the effectiveness of Chinese college English teaching, some universities start a trend of changing their English curriculum.

For instance, in Dalian Maritime University, in response to market requirements, all departments offer different English-related courses. Department of International Economics and Trade makes Advanced English Speaking a compulsory course; Law majors have to attend Basic English Writing; Maritime English is a must for majors of General Navigation. Fudan University asks students to learn English for three terms. Given students' different English levels, they can choose to study one or two terms of General English, then, for the rest two or one term, they can attend Specialized or Applied English.

As a result of the above changes, a higher expectation on English teachers is unavoidable. Under the pressure, some teachers begin to teach Metallurgical English, Legal English and English for Mechanical Engineering, etc. Or, they can choose to give place to $\mathrm{PhDs}$ who have profound specialized knowledge, experience of studying abroad and good English proficiency.

To try a new subject or to leave is a choice all English teachers have to make in the near future. 
To start a new subject means the teacher has to master a lot more skills other than teaching methodology, including the basic knowledge of the students' subject area, syllabus design, courses and materials design, testing and evaluation and so on.

To be qualified for teaching English for students to learn another subject, teachers has to take preservice trainings, which tend to be highly subject-specific and time-consuming. School policy makers and curriculum designers are, though eager to carry out a reform, still not fully aware of the importance of teacher education. In-service teachers who are now teaching General English should spare time and efforts to make a learning plan and get ready for the fundamental change to come. Fortunately, many well-known universities in China and abroad have online courses, among which teachers could choose to attend according to their own interests or needs.

\section{B. Internet: a Catalyst for ELT Development}

The e-times bring new challenges and duties to language teachers. The entry of Internet has been dramatically impacting the traditional English teaching in the following three aspects:

(1) Users of English have increased. David Graddol's study found that, in 2000, there were about a billion English learners, but a decade later the number doubled. The study also suggested over 80\% of information on the internet was in English[7]. The number of non-native English speakers has far surpassed that of native speakers. As a result, the demand and requirement for qualified teachers to instruct students in English have increased too.

(2) The Internet is also increasingly changing or updating lexical, phonetic, syntactic standards of English. For example, the fast living and working pace brought by the Internet has led to an upsurge in English abbreviations. It is easier to form a gap between English teachers, who were equipped with formal and theoretical knowledge in normal universities, and the students, who think it "cool and fun" to use modern English.

(3) The Internet offers the students channels to contact directly with native English speakers through emails, blogs and Facebook, which have blurred the boundaries between nations. Internet also helps them to get vivid cultural background, authentic language materials, which are much natural and functional. Students not only improve their listening and speaking ability, but also learn the western culture. Teachers have to stride into the world of technology and keep pace with students' improvement and gain more true-to-life English knowledge.

Both the self-growth of ELT and the Internet have assigned English teachers in Chinese higher education the task of professional development. These are motive power from the outside-the educational system and the society, according to Grundy and Robison[1]. The other driving force of TPD is from teachers themselves. The author of this paper suggests English teachers ride the waves in the endless turmoil, choose a second major in a virtual university and clear the obstacles in the way of ELT development.

\section{Model of TPD based on ODL}

In recent years, teacher professional development is an important field in which open and distance learning has been adopted for teacher training, notification of academic updating, and cross-disciplinary study in particular subjects. Division of Higher Education of UNESCO provided many examples showing that teacher education by distance education may have profound impact on the development of national education systems in developing countries, such as China, India, Mongolia, Nigeria and South Africa. It is time to make full use of the opportunities ODL provides to effective development for teachers. But, how can the education practitioners best take advantage of the plenty distance resources and what model is most welcomed?

A most important outcome of the modern technology is that it entails more interaction options than ever before. Besides, learning is actually a process of interaction between learners and knowledge. The model to be introduced in this part is therefore a complicated interaction between different parties who are involved.

Michael Moore introduced three types of interaction in distance learning: learner-learner, learner-instructor and learner-content[8]. In addition to Moore's conclusions, another relationshiplearner-teacher in practice-is necessary in TPD. Since this paper is concerned about teacher 
education, the term "learner" in the following part refers to "teachers as learners" who participate in ODL for profession development.

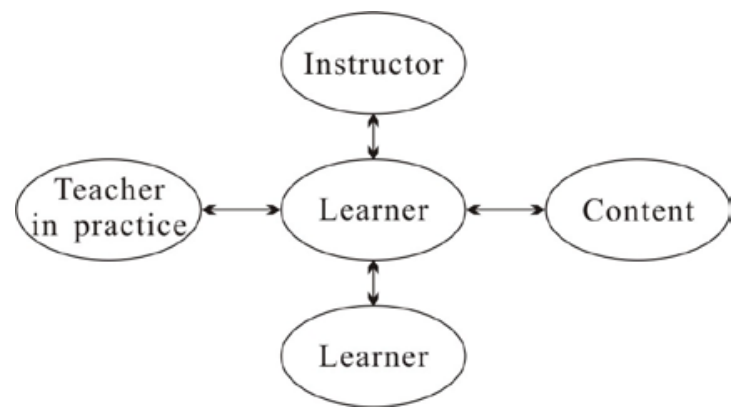

Figure 2. Types of interaction in the model.

\section{Learner-Learner Interaction}

Learners can help each other learn. Collaborative learning research reveals that co-learners can produce deeper learning than if they study individually. In this type of interaction, learners can:

- contact another learner or form a group with or without the real-time presence of an instructor;

- use tools such as BBS, e-mails, online conferences, and chat rooms to share information or materials;

- conduct discussions and brainstorming;

- do collaborative assignments online.

- reflect on their own learning schedules in comparison with peers' progress;

- overcome isolation and strengthen relationship with the group;

- encourage collaborative thinking when questions are raised within a chatting group.

A major problem in this category is the lack of interaction among dispersed learners. This barrier may be overcome through: (1) assigning a social worker to monitor learners' activity; (2) putting learners into small groups and choosing a sociable group leader to construct a positive atmosphere; (3) giving more group tasks than individual assignments.

\section{Learner-Instructor Interaction}

It has been found that, in face-to-face teaching, teachers' verbal (giving positive comments, conversing with students like friends, humor) and nonverbal (eye contact, body language and facial expressions) communication methods can shorten the psychological distance with their students, leading to increased learning. The physical distance that exists in ODL makes interaction between the instructor and learners more than necessary.

Learner-instructor interaction includes:

- the instructor sets a time for video conferences, sessions or seminars to answer questions or have discussions in which a learner can observe the interaction between the instructor and other learners and reflect on himself;

- the instructor provides information, helps learners find materials and gives feedback on performance through emails or BBS;

- learners ask the instructor questions and demonstrate what they have learned;

- learners submit e-coursework and the instructor make comments, give feedback electronically or discuss online, if necessary;

- the instructor monitor performance during web-based work for one or more learners and make on-the-spot evaluation.

Moore pointed out that the transactional distance might cause communication gaps, which require special behavioral patterns. Therefore, the instructor has to ensure that a minimum and maximum amount of "dialog” takes place in the course study.

\section{E. Learner-Content Interaction}

Learner-content interaction takes place when learners internalize the new knowledge by assimilation and accommodation. It is a bidirectional act happens between the new knowledge and 
the prior knowledge. Moore suggested that, without this type of interaction, there could be no education.

Learning with this type of interaction can take place in these ways:

- reading a textbook distributed by the distance education institute;

- using a video or audio clip to learn;

- viewing online text materials and clicking from one page to the next;

- practising what the learner has learned in real situations or in fulfilling a coursework;

- reflecting in and questioning their prior believes and understandings;

In this model, teachers are learners, who belong to the category of adult learners. They are special, as Malcolm Knowles's theory of andragogy assumes the adult learner as someone who: (1) has an individual learning plan and method and can direct his own learning, (2) has a reservoir of life experiences that provides basis for learning, (3) is most interested in learning subjects having immediate relevance to his work and/or personal life, and (4) responds better by internal than external factors[9].

According to Malcolm Knowles's descriptions, it is essential to ensure that the content delivered to the learner is relevant to, and can be immediately applicable in, his life and work. The content has to keep up with the changing times.

\section{F. Learner-Teacher in Practice Interaction}

Open and distance learning can expand beyond the traditional environment with just the instructor, content, and learners. The Internet enables learners to communicate with successful and excellent inpractice teachers who are doing well in the areas which learners expect to excel in.

"Teacher in practice" here refers to a teaching expert, who has insights into and rich experience in a specific subject or course. For instance, learners, who attend an online course to prepare for teaching English to Nursing majors, may be eager to see how an experienced teacher would teach the course Practical Oral Medical English to Nurses.

Examples of this type of interaction are:

- learners learn by observing a video clip of a teaching demonstration given by an expert teacher;

- learners reflect on their own practice while or after watching how the expert teacher teaches;

- in web-based forums and communities, learners raise questions to the teaching expert to solve problems learners have in work;

- learners share information with the expert who is interested in the particular topic;

- the expert puts teaching problems he met onto the discussion sites, where learners could provide an answer or learn how these problems could be solved.

The interaction with teacher in practice is particularly needed when learners have learned much theoretical knowledge but have a hard time connecting theories to actual practice. To get learners fully engaged in the interaction, the virtual teaching institute should play a positive role of making full use of its social network, finding willing teacher experts of different areas and building an online community to connect learners and expert teachers.

In this model of TPD, distance learning technology is of the utmost importance. None of the four types of interaction functions independently. To the contrary, they are closely interrelated to work as a whole. Confined to the length of this paper, a fifth type of interaction-learner-himself (mainly characterized by doing self-reflection) - is not discussed as a separate category, but scattered among the four major types.

\section{Conclusion}

This paper has examined the relationship between teacher professional development and open and distance learning, the urgency of TPD and how modern communication technology could break constraints on time and distance in the development of teachers.

To achieve success in TPD, educators have to overcome psychological and communication gaps that is usually associated with the geographic distance. To encourage closeness, the interactive functions of the Internet must be fully used. In designing distance learning courses, the teaching institute should consider Moore's framework of interaction: learner-learner, learner-instructor; and 
learner-content. In addition, a fourth type of interaction identified in this paper should be considered: learn-teacher in practice. By closely linking the four types of interaction in structuring its courses, the virtual teaching institute can expect to achieve unique benefits offered by the distance-learning format.

\section{Acknowledgment}

This paper was made possible through the inspiration, encouragement and support from my colleagues and family. My deepest and sincerest gratitude goes to them. I would like to extend my thanks to Michael Moore and those whose works I referenced in completing this paper. Their scholarly directions provided me with a general picture of this topic and without which this paper cannot come into being.

\section{References}

[1] S.Grundy and J. Robinson, “Teacher professional development: themes and trends in the recent Australian experience," in International handbook on the continuing professional development of teachers, C. Day and J. Sachs, Eds. Maidenhead: Open University Press, 2004, pp. 146-166.

[2] T. Y. Chen, “Self-training for ESP through action research,” English for Specific Purposes, vol. 19, Dec. 2000, no. 4, pp.389-402 (14), doi: 10.1016/science.000089.

[3] R. Howard and G. Brown, “Teacher education for languages for specific purposes,” Clevedon: Multilingual Matters Ltd., 1997.

[4] A. Waters, “Teacher-training course design: a case study,” ELT Journal, vol 42, issue 1, 1988, pp. 14-20, doi: 10.1093/elt/42.1.14

[5] S. Stryker and B. L. Leaver, "Content-based instruction in foreign language education: models and methods,” Washington DC: Georgetown University Press, 1997. 